\title{
The significance of bubble structures in borehole samples of fine sand
}

\author{
CHAPLOW, R. (1974). Géotechnique 24, No. 3, 333-344.
}

\section{G. E. Rawlings, Binnie and Partners, London}

I wish to add to Chaplow's Paper on bubble structures as a recent site investigation in North Wales has provided excellent examples of the same phenomenon. However, in this case they were developed in much finer grained deposits and it is considered that they were probably caused by the pressure of gas coming out of solution on stress relief during drilling.

During the investigation for the Central Electricity Generating Board's Dinorwic pumped storage scheme at Llanberis in 1972-3 diamond drilling and percussive boring were carried out by Soil Mechanics Limited through slate tips in the Dinorwic Quarry to sample the underlying materials (Fig. 1). The investigation was required in order to assess the stability of the tips during the rapid fluctuations in the level of the planned lower reservoir formed from the existing Llyn Peris. From previous work at either end of the lake it was anticipated that the tips would be underlain by peats, organic silts, lacustrine silts and silty clays with some localized gravels. Therefore, any method of sampling had to cope with the recovery of such sediments from depths in excess of $35 \mathrm{~m}$. Moreover it was considered desirable to obtain a continuous sequence of samples through the deposits.

In practice the optimum method of recovering samples was found to be by using a conventional double tube core barrel to drill through the slate tips to the tip/sediment interface and then, as at Lar, by using a Mazier core barrel to obtain continuous undisturbed samples in the underlying sediments. These methods proved to be remarkably successful although towards

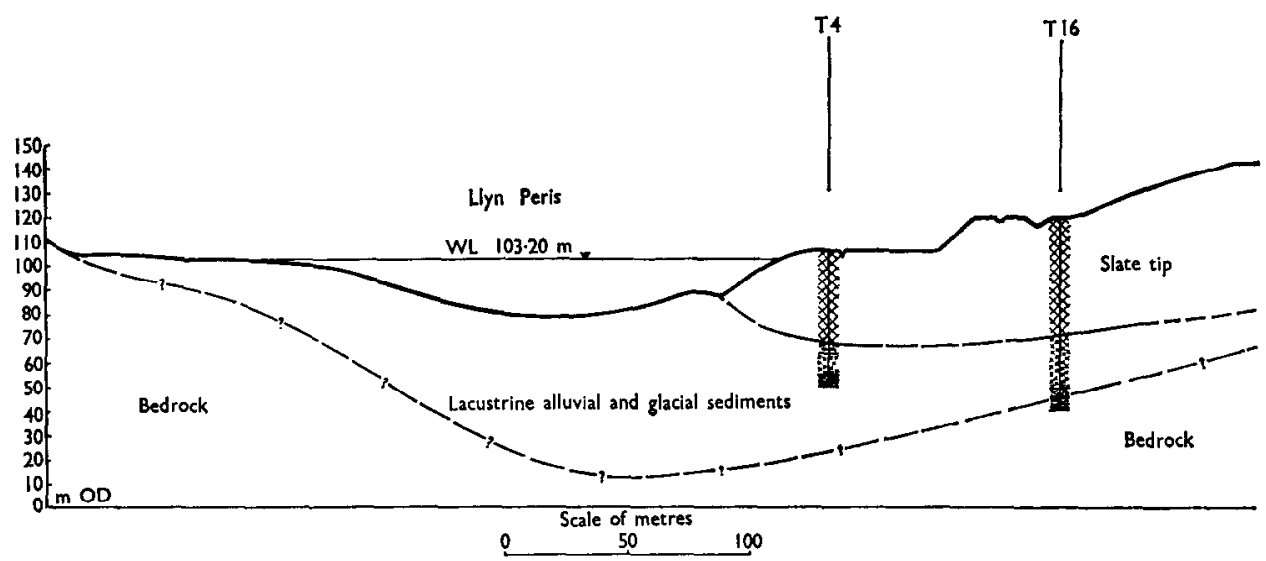

Fig. 1. Section through Dinorwic Quarry slate tip 


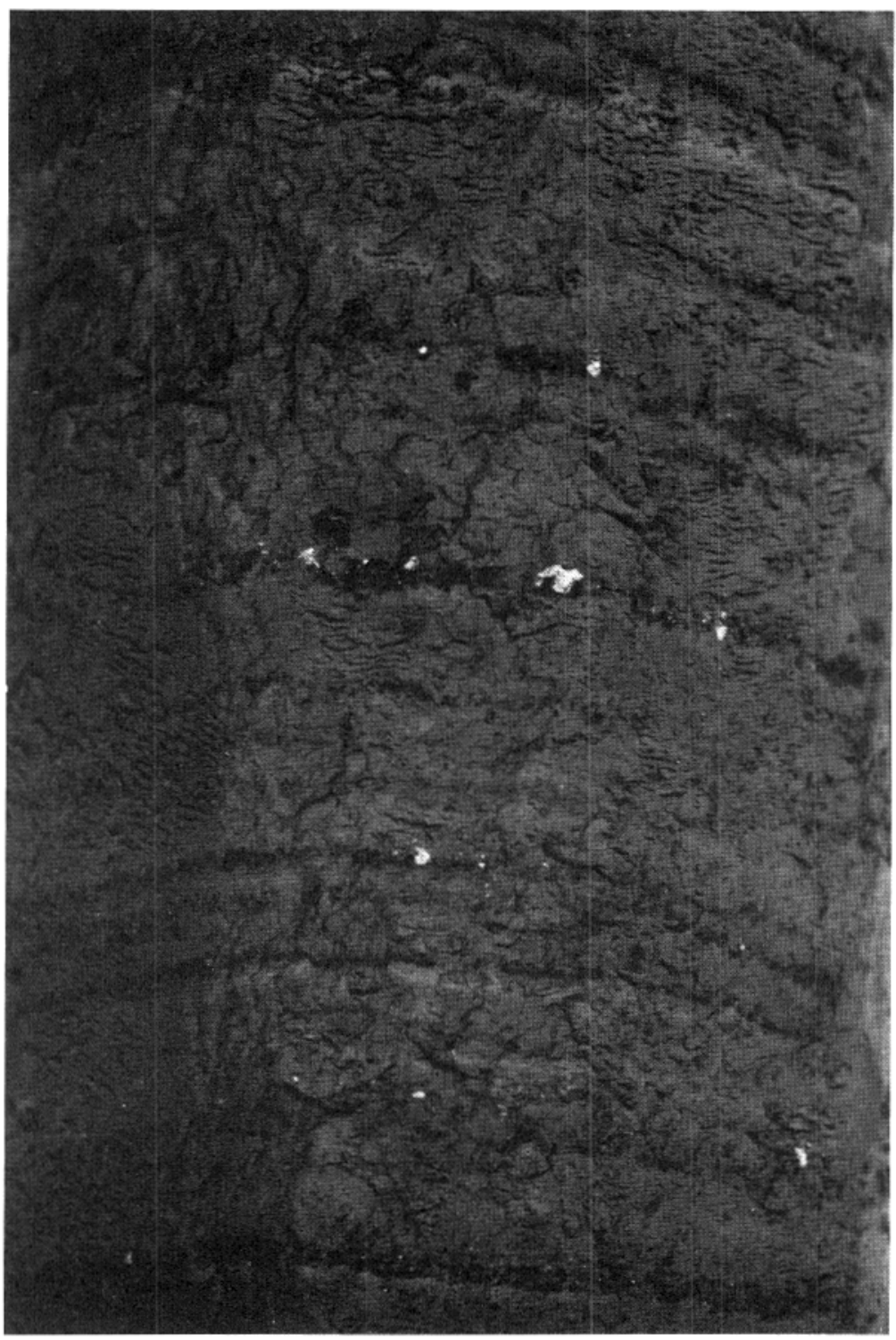

Fig. 2 (above). Mazier core sample showing interbedded silt and peat/organic silt with the development of vivianite within the organic horizons. The core is $107 \mathrm{~mm}$ in diameter

Fig. 3 (right). Mazier core sample (107 mm diameter) of disturbed varved silts. $40.45 \mathrm{~m}$ of slate quarry waste overlies these sediments

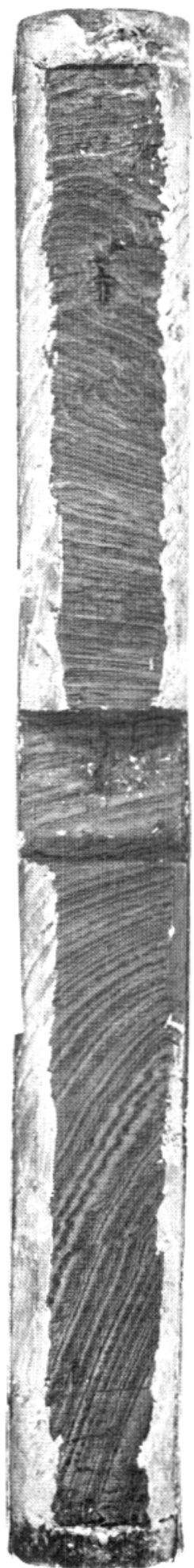




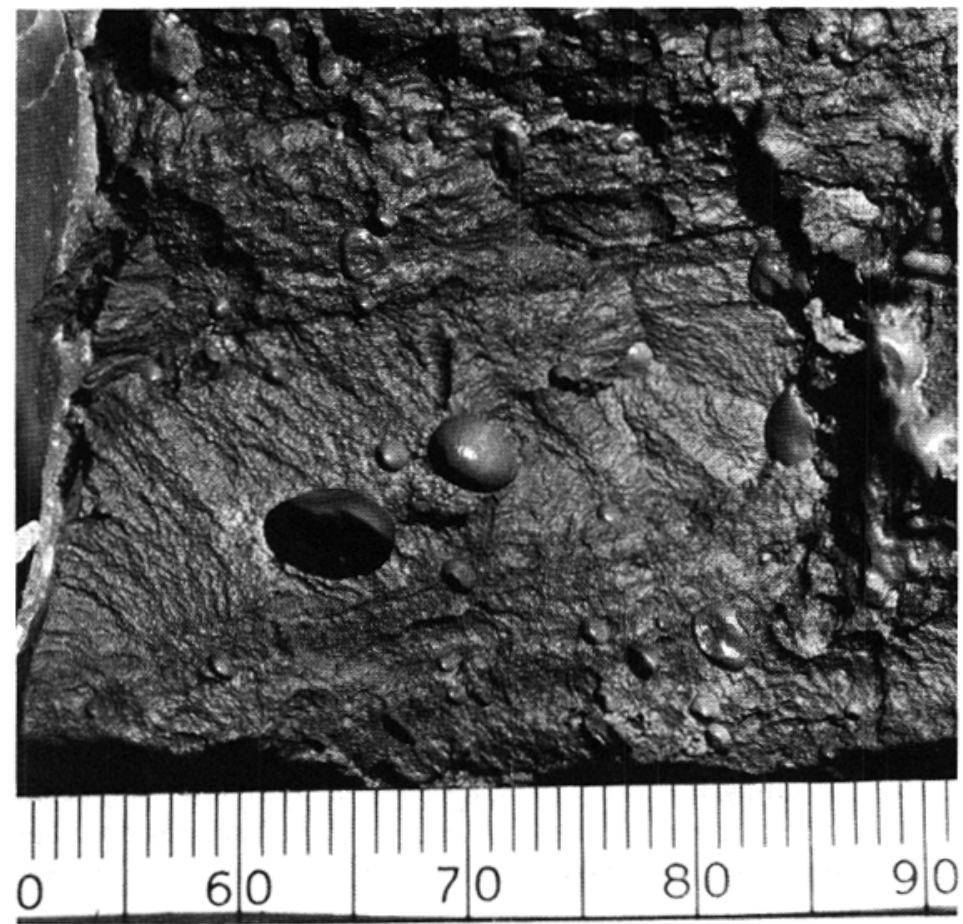



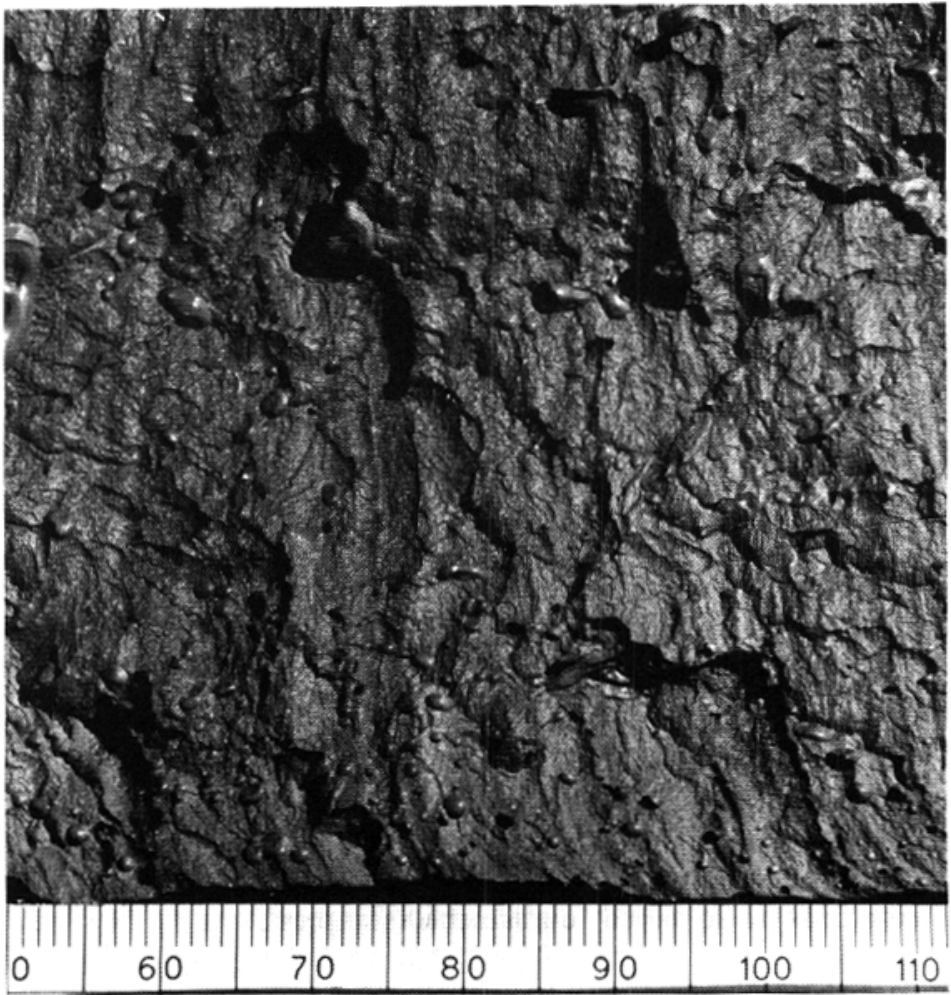

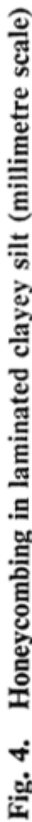


the end of the contract it was found to be more economic to form holes in the tips with a shelland-auger rig. Sections through the Mazier cores are shown in Figs 2 and 3.

On removing the cores from the Mazier barrel liners for description, many of the silty horizons were found to show a 'honeycomb' structure (Fig. 4). This was widespread and took the form of a mass of spherical or flattened elongated cavities distributed through the core. They varied in size from $0.5 \mathrm{~mm}$ to $10 \mathrm{~mm}$ although they were generally in the range $0.5-1.5 \mathrm{~mm}$. They did not appear to disturb the laminations but rather to replace them (Fig. 5). Although they are developed preferentially in some laminae there is no obvious reason for their distribution, but they were not seen close to the organic horizons or those containing vivianite.

The sediments in which these structures were developed at Llanberis were of finer grain size than those described by Chaplow at Lar. They are not believed to be the result of liquefaction or wetting. It is possible that the gases generated by the decomposition of the organic horizons within the sediments were forced into solution as loading by the tip waste occurred. There is no obvious explanation for the size of the structures formed except that there did seem to be a tendency for larger cavities to occur within softer sediments.

Similar honeycombing was seen in piston samples of soft silts and silty clays recovered at a shallow depth from the bed of Llyn Peris.

Despite this apparently simple explanation, bubble-structures are only sparsely recorded in the literature. Certainly the many experienced soil mechanics engineers and geologists who were shown the Dinorwic samples had not seen similar structures previously. This may be an illustration of the improved sampling techniques now available; conventional silt samplers produced only poor disturbed samples at Dinorwic where the Mazier barrel achieved one hundred per cent success. At this stage, without verification from in situ exposures or from laboratory testing, it cannot be said with any certainty that the 'bubbles' were definitely formed during sampling.

If the structures were present in the sediments before sampling then the Mazier coring has produced very good undisturbed samples. If the structures did develop during coring one must consider the samples as disturbed and test results must be treated with caution.

It would be useful to hear of similar experience gained elsewhere in the sampling of these types of sediment.

\section{Author's reply to Rawlings}

I should like to thank Rawlings for his contribution and would agree with him that the bubble structures encountered in the clays at Dinorwic are likely to have been formed by release of dissolved gases during unloading of the samples. The occurrence of bubble structures formed either by this process or by the processes postulated for the Lar sands is likely to be more widespread than is, at present, appreciated. The presence of the bubble structures is only now being observed due to the practice of splitting and logging, in detail, continuous soil samples obtained during the early stages of site investigations. This practice is to be strongly recommended, not only as it provides a means of rapidly gaining an appreciation of the detailed geological succession at any site and hence aids in the design of any subsequent sampling and testing programme, but also it reveals the presence of forms of sample disturbance, including the formation of bubble structures, which will significantly affect the reliability of results obtained from tests on so called 'undisturbed samples'. 